Attention, Perception, \& Psychophysics

Attention, Perception, \& Psychophysics

Listening to music reduces eye movements

\begin{tabular}{|r|l|}
\hline Journal: & Attention, Perception, \& Psychophysics \\
\hline Manuscript ID: & PP-ORIG-14-004.R1 \\
\hline Manuscript Type: & Original Manuscript \\
\hline Complete List of Authors: & $\begin{array}{l}\text { Schäfer, Thomas; Chemnitz University of Technology, Department of } \\
\text { Psychology } \\
\text { Fechner, Jörg; Anglia Ruskin University, }\end{array}$ \\
\hline Keywords: & $\begin{array}{l}\text { attention, eye movements and visual attention, music cognition, sound } \\
\text { recognition }\end{array}$ \\
\hline
\end{tabular}

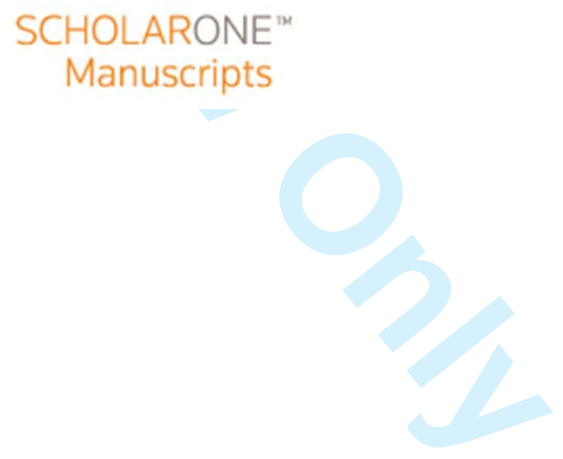




\section{Listening to music reduces eye movements}

Thomas Schäfer ${ }^{1}$ and Jörg Fachner ${ }^{2}$

${ }^{1}$ Chemnitz University of Technology, ${ }^{2}$ Anglia Ruskin University

\section{Author note}

Thomas Schäfer, Chemnitz University of Technology, Department of Psychology, Chemnitz, Germany.

Jörg Fachner, Anglia Ruskin University, Department of Music and Performing Arts, Cambridge, UK.

Correspondence concerning this article should be addressed to Thomas Schäfer, Department of Psychology, Chemnitz University of Technology, 09107 Chemnitz, Germany; e-mail: thomas.schaefer@psychologie.tu-chemnitz.de; fax number: 0049371 531835568 , telephone number: 004937153135568 


\begin{abstract}
Listening to music can change the way people visually experience the environment, probably as the result of an inwardly directed shift of attention. We investigated whether this attentional shift can be demonstrated by reduced eye movement activity and if so, if that reduction depends on absorption. Participants listened to their preferred music, to unknown neutral music, or to no music while viewing a visual stimulus (a picture or a film clip). Preference and absorption were significantly higher for the preferred music than for the unknown music. Participants exhibited longer fixations, fewer saccades, and more blinks when they listened to music as compared to when they sat in silence. These effects tended to be more pronounced when the music was preferred and absorbing than when it was unknown. Thus, reduced eye movement activity can be considered a physiological indicator of an attentional shift from the outer to the inner world (i.e., to emotions and memories evoked by the music).

Keywords: eye movements, music, music preference, absorption, attention
\end{abstract}




\section{How Music Affects the Processing of Endogenous and Exogenous Stimuli}

The effects of music listening on physiological, emotional, and behavioral variables have been receiving increasing attention in psychological research. Listening to music is a ubiquitous everyday behavior that requires many of the listener's psychophysiological resources (see, e.g., North \& Hargreaves, 2008; Zatorre \& Peretz, 2001). People in the Western world listen to music for hundreds of different reasons, the most important being self-awareness and the regulation of mood and arousal (see Schäfer, Sedlmeier, Städtler, \& Huron, 2013). There are also effects of music listening that unfold rather unconsciously. One of the most intriguing of these effects is the alteration of processing of sensory information, such as visual (spatial) and temporal magnitudes. There are many studies that have demonstrated how music can change the way listeners experience space and time, including both experimental investigations (e.g., Bailey \& Areni, 2006; Droit-Volet, Bigand, Ramos, \& Bueno, 2010; Kellaris \& Mantel, 1996; Lopez \& Malhotra, 1991) and subjective reports collected with interviews (e.g., Fachner, 2011a; Gabrielsson, 2001, 2011; Herbert, 2011, 2013). Regarding the representation of time, music typically shortens the estimated length of temporal durations-an effect that is even more pronounced when the listener likes the music used in the study (see Schäfer, Fachner, \& Smukalla, 2013, for an overview). In addition, it is known from subjective reports that musical experiences can cause feelings of timelessness or time dilation. Regarding the representation of visual information, there are data only from subjective reports showing that music can trigger experiences such as spatial mental images or space ceasing to exist (e.g., Becker-Blease, 2004; Gabrielsson \& Lindström Wik, 2003; Gromko, 2004; Herbert, 2011, 2013; Tart, 1971).

Some scholars have tried to explain those effects by arguing that music distracts attention from the processing of sensory information. Attention is instead directed to 
certain thoughts, memories, and emotions that are elicited by the music. In other words, music causes attention to turn away from the environment (exogenous stimuli) and toward inward experiences (endogenous stimuli; Fachner, 2011b; Herbert, 2011, 2013). That shift in attention should be more pronounced the more captivating the music and the more absorbed the listener, such as when listening to strongly preferred music. While there is generally agreement about the role of attention in the effects of music on the representation of time-specifically, that music distracts attention away from the processing of time-there is an obvious lack of research about the role of attention in the effects of music on the processing of visual information (for a summary, see Schäfer et al., 2013). Moreover, there is even a lack of objective empirical data about the changes that occur with the experience of spatial information under the influence of music. Our aim with the present paper is to address this gap by (1) providing empirical data on physiological changes in the processing of visual information under the influence of music and (2) investigating the role of attention in the altered processing of visual information.

\section{The Role of Attention in Music-Induced Changes of Stimulus Processing}

There are many theoretical approaches that can explain why music shortens or lengthens the perception of time intervals. Many of these deal with the idea that attention can be distributed to multiple processes, such as listening to music and estimating temporal durations (e.g., the attentional gate model; Zakay \& Block, 1997). Music can distract attention from the processing of temporal tasks, and the extent to which this happens depends on variables such as music preference, familiarity, emotional connotation, and the arousal potential of the music. In contrast, there are no approaches that can explain the effects of music listening on the experience of space. Schäfer et al. (2013) discussed two lines of evidence that may be helpful to develop an 
explanation. First, they referred to Blood and Zatorre (2001), who had demonstrated that music-induced frisson experiences (typically indicated by goose bumps or shivers down the spine) significantly reduce neuronal activity in the occipital lobe, which is responsible for visual processing. The reduction of neuronal activity did not show up with control music that did not cause frisson experiences. This result may explain experiences such as space ceasing to exist and indicates that attentional resources shift away from the processing of visual input-probably toward the processing of inner events, such as certain associations, emotions, or memories elicited by the music. The second line of evidence comes from studies showing that attention turns inward during altered state of consciousness (ASC) experiences (e.g., Cardena, 2005; Rouget, 1985; Zingrone, Alvarado, \& Cardena, 2010; see also Vaitl et al., 2005). Given that music can elicit ASC experiences (e.g., Fachner, 2011b; Herbert, 2011, 2013; see also Kreutz, Ott, Teichmann, Osawa, \& Vaitl, 2008), this is another hint that there could be an inwardly turned shift of attention under the influence of music-particularly under the influence of music that is captivating or absorbing.

To sum up, there is evidence from subjective reports about changes in the experience of space under the influence of music listening; most of these reports refer to the experience of space (i.e., the environment or objects in the environment) fading into the background or ceasing to exist. A shift in attention may be responsible for these experiences but empirical evidence supporting this notion is lacking. We set out to investigate changes in attentional focus under the influence of music listening. Specifically, we define a distribution of attention along an exogenous-endogenous axis. Exogenous attention is commandeered and governed by external input from the environment. Endogenous attention is commandeered and governed by inner stimuli and events such as thoughts, emotions, imaginings, or memories. This taxonomy is 
similar to that of external and internal attention (Chun, Golomb, \& Turk-Brown, 2011), where external attention "refers to the selection of sensory information, as it initially comes into the mind, generally in a modality-specific representation and often with episodic tags for spatial locations and points in time" and internal attention "refers to the selection and modulation of internally generated information, such as the contents of working memory, long-term memory, task sets, or response selection” (p. 77). This differs from our classification in that we understand endogenous attention a little more broadly: it not only covers goal-directed attention but also attention to spontaneously emerging memories or imaginings. For instance, a stimulus such as a piece of music may cause the listener to indulge in reminiscences, which would attract attention but is not a goal-directed deployment of attention. Note that our classification is different from the distinction of exogenous/endogenous cuing (Posner, Snyder, \& Davidson, 1980), where "endogenous" cuing is observer driven but still directed to external stimuli.

Since it is known that music has great power to elicit emotions, memories, and thoughts (e.g., Juslin \& Laukka, 2003, 2004; Juslin \& Sloboda, 2001; Schäfer, Smukalla, \& Oelker, 2013), we hypothesize that music can induce a shift from exogenous to endogenous attention. In addition, we suppose that such a shift should be more pronounced the more the music is captivating or absorbing to the listener, where absorption can be defined as "an effortless, non-volitional quality of deep involvement with the objects of consciousness" (Jamieson, 2005, as cited in Herbert, 2011, p. 5).

\section{Using Eye Tracking as an Indicator of Attentional Changes}

How can one obtain an objective measure of altered experience of space, which is induced by a shift of attention? We argue that the attentional shift from outward to inward should be detectable in reduced attention to exogenous stimuli, which should, in turn, be detectable in reduced eye movement activity directed toward exogenous 
stimuli. Eye movements have shown promise as an indicator of states of absorption, distraction, and detachment from the surrounding stimuli (e.g., Lavine, Sibert, Gokturk, \& Dickens, 2002; Schleicher, Galley, Briest, \& Galley, 2008; C. N. Smith, Hopkins, \& Squire, 2006; see also D. T. Smith, Schenk, \& Rorden, 2012). Stern, Walrath, and Goldstein (1984) demonstrated that sustained visual attention to external stimuli is associated with a decrease in blinking rate. Oh, Han, Peterson, and Jeong (2012, p. 1) concluded that "spontaneous eyeblinks likely signal a shift in the internal cognitive or attentional state." In addition, reduced eye movement activity can indicate a hypnotically induced state of staring (Kallio, Hyönä, Revonsuo, Sikka, \& Nummenmaa, 2011).

In the past, eye tracking has been used to investigate the influence of music and sound, respectively, on reading (Cauchard, Cane, \& Weger, 2012; Dan, Xue, Xiaodong, Li, \& Na, 2008; see also Rayner, 1998, for an overview) and video exploration (Coutrot, Guyader, Ionescu, \& Caplier, 2012). Cauchard et al. (2012) found that background music had virtually no effect on the process of reading or on eye movement while reading. In contrast, Dan et al. (2008) found that music can improve or disturb the reading process and leads to a lower frequency of fixations. Coutrot et al. (2012) investigated the exploration of videos (action movies, drama, documentary film, dialogues) with and without their original soundtrack and found that in the soundtrack condition, "the eye positions of participants are less dispersed and tend to go more away from the screen center, with larger saccades" (p. 9). Participants in this condition also made longer fixations. Zou, Müller, and Shi (2012) investigated visual scanning and found that sound events - simple beeps that were spatially uninformative about the presented stimulicaused longer fixations and fewer saccades. The authors mentioned a "freezing effect" of 
visual scanning due to the sound events, which actually enhanced visual search efficiency.

\section{Aim of the Present Study}

Taken together, these results support our notion that listening to music reduces eye movement activity while looking at stimuli in the environment. Notably, in the above-mentioned studies (Coutrot et al., 2012; Zou et al., 2012), there were "target regions" or "salient regions" and the authors argued that such regions might attract participants' gaze for longer time periods in conditions where sound is present. Another straightforward explanation would be that attention is distracted from the processing of the stimuli. Beanland, Allen, and Pammer (2011) made a similar argument. They found that music can facilitate visual awareness and reduce inattentional blindness, and they suggested that this result occurred because music distracted participants from the visual task. These authors further concluded that the mechanisms of how music affects visual awareness remain unclear but that music may lead to more broadly distributed attention. We argue that music attracts the listener's attention and directs it toward the music and its accompanying thoughts, memories, and emotions. Yet, we posit that such a shift in attention occurs at the expense of having attention available for the processing of outer visual stimuli. Beanland et al. (2011) showed that music can help prevent inattentional blindness by loosening the attentional focus from a visual task. This is not a demonstration of a "broadening" of attention but might show that attention is no longer tightly focused on a specific external stimulus.

We believe that eye tracking is a promising option to investigate the distribution of attention under the influence of music. Specifically, given the different arguments discussed above, we can make two alternative predictions: If music creates an inward shift of attention, we should find "decreased" eye movement activity (i.e., lower rate of 
saccades, longer fixations, but higher rate of blinks), whereas if music broadens attentional focus, we should find "increased" eye movement activity (i.e., higher rate of saccades, shorter fixations, lower rate of blinks) or at least no difference from situations where no music is played. In addition, the influence of music on attention should be stronger when the music is more absorbing. It has been shown that the degree to which a person likes the music played does not affect eye movement in reading and text comprehension tasks (Johansson, Holmqvist, Mossberg, \& Lindgren, 2012), but there have been practically no studies on the influence of music on eye movement activity in nonreading situations. Because reading and text comprehension are cognitively quite demanding tasks where absorption in music is unlikely to occur much, we set out to investigate situations that are naturalistic but not too demanding. We therefore had participants look at a picture or watch a short film clip while they listened to music. Absorption should be heightened through the use of their favorite music, which they brought along to the study (see Rhodes, David, \& Combs, 1988). To measure eye movement activity we recorded the mean duration of fixations and the frequencies of saccades and blinks per second. Although other measures are frequently used as wellsuch as latencies or distances-we decided to use these simple measures because they are easy to interpret.

\section{Methods}

\section{Participants}

Participants were 87 students (70\% women) from the psychology department, 18 to 33 years old $(M=22.6 ; S D=3.2)$. There were no special requirements for participation. They were told to bring a piece of their favorite music to the study, which was copied to the experimental computer before the session. The pieces people brought were of different musical genres; most often it was rock or pop music (rock 33\%, pop 
19\%, electro/house 13\%, classical 11\%, jazz 6\%, black/hip-hop 6\%, metal 4\%, reggae/soul $4 \%$, indie $2 \%$, chanson $2 \%$ ). Participants were recruited via the university's email distribution lists. They received course credit for their participation.

An a priori power analysis was run to calculate the required sample size (using G*Power 3.1; Faul, Erdfelder, Lang, \& Buchner, 2007). Since there were no preliminary analogous studies that could have been used to estimate a population effect, we used a medium effect size $(f=.25$; see Cohen, 1988$)$. Gaining a power of $80 \%$ would have required a sample size of 128 for the stimulus factor (picture vs. film) and 158 for the music factor (no music, neutral music, favorite music). Yet eye tracking is effortful and time consuming for both participants and researchers, so we were only able to test the 87 students mentioned above-leaving us with an actual power of $63 \%$ for the stimulus factor and $52 \%$ for the music factor.

\section{Apparatus}

Participants were seated $55 \mathrm{~cm}$ in front of a computer screen and were asked to place their head on a holder to fasten it for the eye tracking. The 19-inch computer screen had a resolution of $1,280 \times 1,024$ pixels (aspect ratio of 4:3) and a refresh rate of 60 Hz. An infrared eye-tracking system (REDIII; SensoMotoric Instruments; sampling rate: $60 \mathrm{~Hz}$, tracking resolution: $0.03^{\circ}$, gaze position accuracy: $0.4^{\circ}$ ) was used to record participants' eye movements and its software Begaze was used to calculate the mean duration of fixations and the number of saccades and blinks, each per second.

\section{Stimuli and Procedure}

Sessions started with an introduction to the study, followed by the calibration of the eye-tracking system. For calibration, participants had to fixate on nine fixation crosses on the screen, organized in a 3-by-3 grid, starting and ending with the cross in the middle of the screen. Participants put on headphones (only in the music conditions) 
and received all instructions on the screen. There were three conditions: (1) participants listened to their favorite music; (2) they listened to an unknown neutral piece of music; (3) there was no music. The unknown music was an instrumental piece of the ambient/lounge genre, which is music with a gentle beat and a smooth rhythm that is usually judged as "neutral" or slightly positive in terms of liking (see Schäfer \& Sedlmeier, 2011). The piece (Stephane de Lucia: Divide) had a tempo of 121 beats per minute and was judged by the authors as being of medium complexity. Tempo and complexity were chosen to match the average tempo and complexity of people's favorite music. The pieces people would bring along to the study were expected to be quite heterogeneous so we decided on a tempo of about 120 beats per minute, which is roughly the average tempo of popular music. The music contained no lyrics.

While listening or sitting in silence, respectively, participants were presented with either a picture or a short film clip, each spanning the whole screen (see Figure 1). The picture showed a richly colored digital image of a house by the sea for $45 \mathrm{~s}$. The film scene showed a videotaped road trip on an empty road through an open landscape with sunny weather for $70 \mathrm{~s}$. The two different settings (picture and film) were employed to provide two realistic everyday stimuli of different character (static and moving). The durations ( $45 \mathrm{~s}$ and $70 \mathrm{~s}$ ) were arbitrary except that we tried to avoid a duration of exactly $60 \mathrm{~s}$, which might have caused an anchor effect at $1 \mathrm{~min}$. The film clip was a continuous recording without any cuts because cuts lead to considerable changes in eye movement activity (see Coutrot et al., 2012).
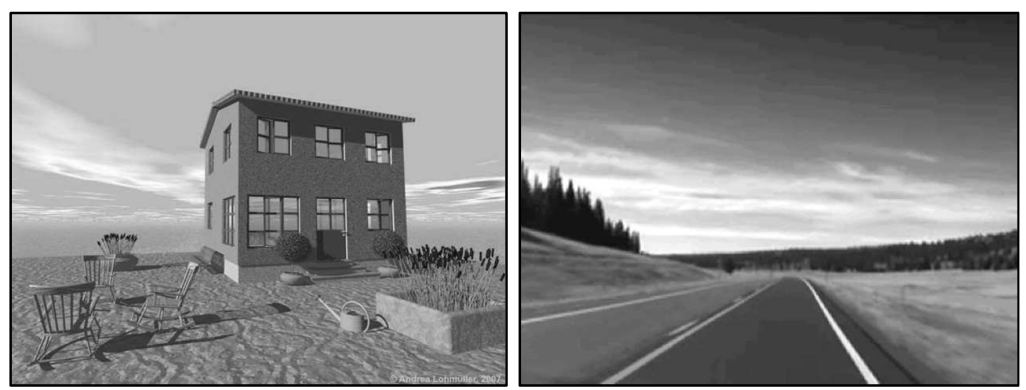
Figure 1. Stimuli used in the study: picture (left) and still from the film clip (right). Note. In the study, both stimuli were in color.

Participants were instructed to look at the picture or watch the film clip, respectively, without any specific task. The music started about $10 \mathrm{~s}$ before stimulus onset. Participants were randomly assigned to one of the six experimental combinations (favorite music with picture, favorite music with film, neutral music with picture, neutral music with film, no music with picture, no music with film).

To assess if their favorite music was more enjoyable than the neutral music selected by the experimenters, we asked participants to rate how much they liked the pieces on a 10-point Likert scale ranging from 1-not at all-to 10-very much. To measure music-related absorption, we additionally administered an absorption questionnaire to 30 randomly selected participants who were in one of the four music conditions. ${ }^{1}$ The questionnaire consisted of seven items that were adapted from the Tellegen Absorption Scale (TAS; Tellegen \& Atkinson, 1974). The TAS comprises 34 items measuring different facets of absorption, so we adapted and used only the seven items pertaining to music-listening situations ("When listening to the music, I became so involved that I forgot about myself and my surroundings." "When listening, I felt as if my mind could envelop the whole earth." "When listening to the music, I got so caught up in it that I didn't notice anything else." "I was completely immersed in the music and felt as if my whole state of consciousness had somehow been temporarily altered." "When listening to the music, I was wandering off into my own thoughts." "The music reminded me of pictures or moving patterns of color." "I was deeply moved by the music.”). Participants rated their agreement with the items on a 10-point Likert scale from 1-not at all-to 10-yes, very strongly.

\footnotetext{
${ }^{1}$ Although we had planned to gather absorption data from all the participants, we got only this random selection due to a technical problem.
} 


\section{Results}

\section{Music Preference and Absorption}

None of the participants had ever heard the neutral piece of music before. The mean preference for the neutral piece was $5.7(S D=2.2)$; the mean preference for the favorite piece was $9.4(S D=0.8)$, which is a significant difference, $t(59)=12.4, p<.001$. The mean absorption while listening to the preferred piece was $6.0(S D=1.5)$; the mean absorption while listening to the neutral piece was $3.6(S D=1.3)$, which is also a significant difference, $t(29)=8.5, p<.001$. Thus, participants' favorite pieces were enjoyed more and led to stronger absorption than the neutral piece.

\section{Eye Movement Activity}

Table 1 shows the mean duration of fixations and the frequencies of saccades and blinks per second in each condition. In both settings (picture and film), the duration of fixations was shorter, the frequency of saccades was higher, and the frequency of blinks was lower when participants did not listen to music but only viewed the stimulus. Eye movement activity changed significantly under the influence of music: Both the duration of fixations and the frequency of blinks increased, while the frequency of saccades decreased. These differences appear to be more pronounced when participants listened to their preferred music. A series of 3 (music) $\times 2$ (stimulus) analyses of variance revealed a significant effect of the music condition for each of the three measures: duration of fixations, $F(2,74)=12.8\left(p<.001, \eta^{2}=.15\right)$, number of saccades per second, $F(2,74)=17.2\left(p<.001, \eta^{2}=.19\right)$, and number of blinks per second, $F(2,74)=9.1(p<$ $.001, \eta^{2}=.11$ ). There was also a significant effect of the stimulus condition for two of the three measures: number of saccades per second, $F(1,74)=4.1\left(p=.046, \eta^{2}=.03\right)$, and number of blinks per second, $F(1,74)=5.1\left(p=.026, \eta^{2}=.03\right)$, but not for duration of fixations $F(2,74)=1.3\left(p=.255, \eta^{2}=.01\right)$. Participants exhibited fewer saccades per 
second and more blinks per second when they watched the film as compared to when they looked at the picture.

There are two probable reasons for this difference in eye movement activity. First, the picture contained many more details than the film clip so that there was more to explore. Second, the recorded road trip in the film might have drawn participants' visual attention more to the middle of the screen-where a driver would look-than to the periphery. There were no interaction effects between the music conditions and the stimulus conditions: duration of fixations, $F(2,74)=.23\left(p=.80, \eta^{2}=.003\right)$, number of saccades per second, $F(2,74)=.19\left(p=.83, \eta^{2}=.003\right)$, and number of blinks per second, $F(2,74)=.97\left(p=.38, \eta^{2}=.01\right)$

Table 1

Mean Values and Standard Deviations (SDs) of Participants' Eye Movement Data, for the No Music Condition, the Neutral Music Condition, and the Favorite Music Condition

\begin{tabular}{lccc}
\hline Eye movement data & No music & Neutral music & Favorite music \\
$M(S D)$ & $M(S D)$ & $M(S D)$
\end{tabular}

Picture

Mean fixation duration

0.340 (0.149)

$0.478(0.202)$

$0.581(0.284)$

Saccades/second

3.277 (0.625)

2.228 (1.232)

2.029 (1.332)

Blinks/second

0.142 (0.109)

$0.396(0.311)$

0.447 (0.371)

Film

$\begin{array}{llll}\text { Mean fixation duration } & 0.391(0.097) & 0.543(0.280) & 0.589(0.284) \\ \text { Saccades/second } & 2.788(0.701) & 1.944(1.199) & 1.776(1.031) \\ \text { Blinks/second } & 0.171(0.145) & 0.672(0.866) & 0.772(1.02)\end{array}$


2

3

4

5

6

7

8

9

10

11

12

13

14

15

16

17

18

19

20

21

22

23

24

25

26

27

28

29

30

31

32

33

34

35

36

37

38

39

40

41

42

43

44

45

46

47

48

49

50

51

52

53

54

55

56

57

58

59

60

Since there were no interaction effects-and also to increase statistical powerwe combined the data of the two stimulus conditions to visualize the effect of the music manipulation in Figure 2. As can be seen, for each of the three measures, the effect of music on eye movement activity was slightly more pronounced when the music was preferred or absorbing. However, these differences are only nonsignificant tendencies, as indicated by Bonferroni-corrected comparisons and effect sizes (see Figure 2). 

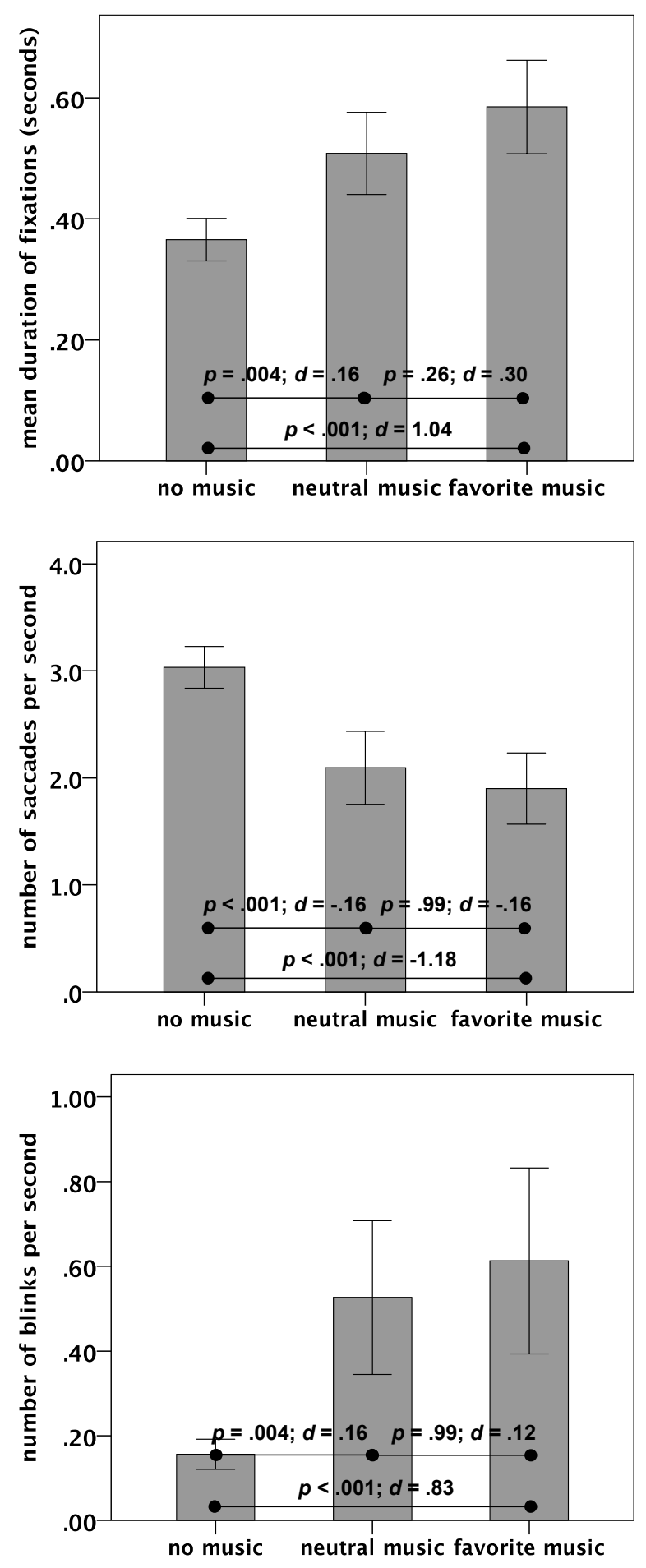

Figure 2. Means and 95\% confidence intervals of mean duration of fixations, number of saccades per second, and number of blinks per second, for the three music conditions. The $p$ values of the differences between groups are based on Bonferroni-corrected comparisons. 


\section{Discussion}

\section{Listening to Music and Eye Movements}

Listening to music has a significant effect on eye movement activity when viewing visual stimuli such as a picture or a film clip: Participants exhibited longer fixation durations, fewer saccades, and more blinks compared to when they viewed the same stimuli in silence.

These results are an initial demonstration that music changes the way we visually experience the world. We obtained these results using quantitative behavioral measures that are more reliable than the extant data from subjective reports about altered experiences of external stimuli under the influence of music listening. The results are in line with the hypothesis of a shift of attention from the outer world (exogenous attention decreases) to the inner world (endogenous attention increases). They do not support the hypothesis that music broadens attentional focus. An inward shift of attention may be a result of music-induced emotions, memories, associations, or imaginings.

The results suggest that the listeners' vigilance might have decreased under the influence of music, because vigilance has been shown to be associated with a higher frequency of fixations (Smith et al., 2006; see also Lavine et al., 2002). Similarly, the finding of higher rates of blinks indicates decreasing exogenous attention (Schleicher et al., 2008). However, since correlation does not equal causation, this is a preliminary inference that calls for further investigation incorporating specific vigilance measures.

\section{The Role of Music Preference and Absorption}

We hypothesized that preferred or absorbing music would intensify the effect on eye movement activity. Listening to one's favorite music can be a very intense experience eliciting even more or stronger emotions or associations than those elicited 
by nonfavorite music, which can lead to distraction and detachment from the outer world. Herbert (2013, p. 16) noted that "music mediates rather than accompanies experiences marked by dissociative and absorbed shifts of consciousness." She further concluded that changed perceptual relationships with surroundings contribute to an important function of music: People use it to "intentionally escape preoccupations or unwanted thoughts." Our results tend to support the notion that the effect of music on eye movement activity is more pronounced when the music is preferred and the listeners is absorbed. However, there were no significant differences between the neutral music condition and the favorite music condition, so we cannot conclude our hypothesis is true.

\section{Potential Biopsychological Mechanisms}

Reduced eye movement activity under the influence of music listening could be an expression of a shift of activation of certain brain regions in the course of an inwardly directed attentional shift. Dietrich (2003) proposed the concept of hypofrontality to explain functional changes in frontal areas of the brain. He argued that the prefrontal cortex, the highest integrating component in a hierarchy of cognitive functions, is deregulated in ASCs by ceasing to function in a "normal" way. This is the hypofrontal (reduced frontal brain activity) state, which can be compared to the state of flow, in which effortless information processing seems to take place. It enables the temporary suppression of the analytical and meta-conscious capacities of the explicit system when a person is relaxed and absorbed in a flood of sensory input, such as music and the thoughts, memories, and emotions that music elicits (Dietrich, 2004). Hypofrontality resulting from intense music experiences may also account for more intense emotions (Kreutz et al., 2008), for pleasure and well-being resulting from musical activities (Lamont, 2011), and for intense experiences with music occurring under the influence of 
drugs (Fachner, 2011a). A recent study investigating eye movements of a highly hypnotizable person demonstrated a phenomenon known in hypnosis, the so-called trance stare, which also seems to be accompanied by changes in the prefrontal areas of the brain (i.e., the dorsolateral prefrontal cortical areas; Kallio et al., 2011). During the "hypnotically induced stare" the "amplitude, velocity and frequency of reflexive saccades were radically suppressed, and the fixation time was increased" (Kallio et al., 2011, p. 5). This is in line with the reduction of eye movement observed in our participants. The eye movement pattern we observed here, similar to the "hypnotically induced stare," seems to represent a physiological marker of a music-induced ASC in which attention is absorbed and focused inward while "trancing" (Becker, 2004) with the music. All this evidence pertains to very intense experiences with music-such as frisson, trance, or ASC-so that we have to make any comparison to the listening situation we employed in our study with caution. It remains an interesting task for future research to investigate whether every kind of music listening leads to alterations to the normal state of consciousness to some degree, as has been discussed by Schäfer, Smukalla, et al. (2013; see also Herbert, 2012; see Vaitl et al., 2005, for a detailed discussion of ASCs). Moreover, the effect of specific pieces of music on absorption may actually be twofold: When the music contains lyrics there may be an effect that is due to the music and an effect that is due to the lyrics. The control piece we used in our study did not contain lyrics whereas the participants' favorite pieces often did. Since the differences between the neutral music and the favorite music were negligible we cannot compare potential differences between music with and music without lyrics. It therefore remains an interesting question whether such differences exist.

\section{Methodological Issues and Limitations}


The present study provides data about the influence of music listening on eye movement activity. Although the results are in line with our hypothesis that music causes a shift from exogenous to endogenous attention, we can only tentatively conclude this hypothesis is entirely supported. The attentional shift was not directly assessed in our study because we had our participants concentrate only on the visual material without completing any secondary tasks (see below). As discussed above, a number of studies have demonstrated a connection between reduced eye movement activity and reduced vigilance or exogenous attention, respectively. Nonetheless, there are also exceptions such as the study by Zou et al. (2012), where reduced eye movement activity led to an improvement in the processing of external stimuli. However, that study used simple sound events (beeps) and not music, which makes it hard to compare its results with those of the present study. In any case, further research is necessary to investigate the characteristics of the assumed exogenous-endogenous axis of attention. In this regard, it would also be interesting to analyze how the effects of such simple sound events on eye movement activity differ from the effects of music, that is, to quantify the effect that is specific to real music. In addition, there are a series of music-related variables that may have specific effects on how music affects attention. We just mentioned the presence of lyrics. Other variables are mood and arousal. In general, people's favorite music can be expected to increase their physiological arousal and improve their mood (see Schäfer \& Sedlmeier, 2011) so that it remains interesting to investigate if potential differences between neutral music and favorite music depend on these two variables.

Whether our findings indicate a potential risk for car drivers, cyclists, or pedestrians who listen to (their favorite) music we consider a question for further research. It is difficult to generalize the results from an eye-tracking study like ours- 
where people are fixed in an apparatus and are confronted with a highly artificial situation-to real-world car-driving situations. Also, our setting did not include any specific tasks participants had to complete and there were no specific targets on the screen they had to pay attention to, which would be quite different in a real driving situation. For instance, Beanland et al. (2011) found that music can even facilitate visual awareness and help prevent inattentional blindness (see also Coutrot et al., 2012).

Note that listening to music in our study was not conceptualized as a secondary task. Participants were meant to listen to the music without any specific purpose, just as they would do at home or in a usual listening situation. There were two reasons for this. First, as Stuyven, Van der Goten, Vandierendonck, Claeys, and Crevits (2000) have demonstrated, secondary tasks—such as tapping at a certain frequency—reduce eye movement activity (although only in visual search settings with specific targets). Second, we hypothesized that listening to music would elicit specific thoughts, memories, or emotions and therefore cause an attentional shift from outward to inward. Combining listening to music with a secondary task would have created a situation not comparable to a naturalistic listening situation and thus would have corrupted this effect.

\section{Conclusion}

To conclude, our study provides an initial demonstration that listening to music affects eye movement activity. The data provide reliable behavioral measurements that can explain extant data about subjective experiences of space under the influence of music. Listening to music reduced eye movement activity in our study, which we assume was due to a shift from exogenous to endogenous attention. Endogenous attention may be heightened because music can elicit specific thoughts, memories, or emotions. The effect of music listening on eye movement activity was expected to be even stronger when people listened to their preferred music that they experienced as being more 


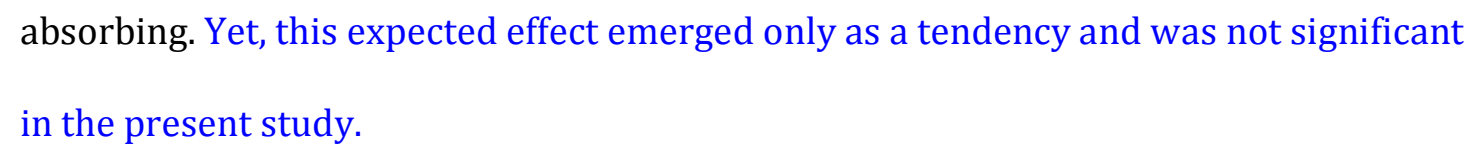


References

Bailey, N., \& Areni, C. S. (2006). When a few minutes sound like a lifetime: Does atmospheric music expand or contract perceived time? Journal of Retailing, 82, 189-202. doi:10.1016/j.jretai.2006.05.003

Beanland, V., Allen, R. A., \& Pammer, K. (2011). Attending to music decreases inattentional blindness. Consciousness and Cognition: An International Journal, 20, 1282-1292. doi:10.1016/j.concog.2011.04.009

Becker, J. (2004). Deep listeners: Music, emotion, and trancing. Bloomington, IN: Indiana University Press.

Becker-Blease, K. A. (2004). Dissociative states through new age and electronic trance music. Journal of Trauma \& Dissociation, 5, 89-100. doi:10.1300/J229v05n02_05

Blood, A. J., \& Zatorre, R. J. (2001). Intensely pleasurable responses to music correlate with activity in brain regions implicated in reward and emotion. Proceedings of the National Academy of Science of the United States of America, 98, 11818-11823. doi:10.1073/pnas.191355898

Cardena, E. (2005). The phenomenology of deep hypnosis: Quiescent and physically active. International Journal of Clinical and Experimental Hypnosis, 53, 37-59. doi:10.1080/00207140490914234

Cauchard, F., Cane, J. E., \& Weger, U. W. (2012). Influence of background speech and music in interrupted reading: An eye-tracking study. Applied Cognitive Psychology, 26, 381-390. doi: 10.1002/acp.1837

Chun, M. M., Golomb, J. D., \& Turk-Browne, N. B. (2011). A taxonomy of external and internal attention. Annual Review of Psychology, 62, 73-101. doi:10.1146/annurev.psych.093008.100427 
Cohen, J. (1988). Statistical power analysis for the behavioral sciences (2nd ed.). Hillsdale, NJ: Erlbaum.

Coutrot, A., Guyader, N., Ionescu, G., \& Caplier, A. (2012). Influence of soundtrack on eye movements during video exploration. Journal of Eye Movement Research, 5, 1-10.

Dan, C., Xue, S., Xiaodong, W., Li, Q., \& Na, J. (2008). An eye movement research of the influence of music on reading. Psychological Science (China), 31, 385-388.

Dietrich, A. (2003). Functional neuroanatomy of altered states of consciousness: The transient hypofrontality hypothesis. Consciousness and Cognition, 12, 231-256.

Dietrich, A. (2004). Neurocognitive mechanisms underlying the experience of flow. Consciousness and Cognition, 13, 746-761.

Droit-Volet, S., Bigand, E., Ramos, D., \& Bueno, J. L. O. (2010). Time flies with music whatever its emotional valence. Acta Psychologica, 135, 226-232.

Fachner, J. (2011a). Drugs, altered states and musical consciousness: Reframing time and space. In E. Clarke \& D. Clarke (Eds.), Music and consciousness (pp. 263-280). Oxford, England: Oxford University Press.

Fachner, J. (2011b). Time is the key-Music and ASC. In E. Cardenas, M. Winkelmann, C. Tart, \& S. Krippner (Eds.), Altering consciousness: A multidisciplinary perspective: Vol. 1. History, Culture and the Humanities (pp. 355-376). Santa Barbara, CA: Praeger.

Faul, F., Erdfelder, E., Lang, A., \& Buchner, A. (2007). G*Power 3: A flexible statistical power analysis program for the social, behavioral, and biomedical sciences. Behavior Research Methods, 39, 175-191.

Gabrielsson, A. (2001). Emotions in strong experiences with music. In P. N. Juslin \& J. O. Sloboda (Eds.), Music and emotion (pp. 431-449). New York, NY: Oxford University Press. 
Gabrielsson, A. (2011). Strong experiences with music: Music is much more than just music. New York, NY: Oxford University Press. doi:10.1093/acprof:oso/9780199695225.001.0001

Gabrielsson, A., \& Lindström Wik, S. L. (2003). Strong experiences related to music: A descriptive system. Musicae Scientiae, 7, 157-217.

Gromko, J. E. (2004). Predictors of music sight-reading ability in high school wind players. Journal of Research in Music Education, 52, 6-15. doi:10.2307/3345521

Herbert, R. (2011). Music listening: Absorption, dissociation and trancing. Aldershot, England: Ashgate.

Herbert, R. (2012). Musical and non-musical involvement in daily life: The case of absorption. Musicae Scientiae, 16, 41-66.

Herbert, R. (2013). An empirical study of normative dissociation in musical and nonmusical everyday life experiences. Psychology of Music, 41, 372-394.

Johansson, R., Holmqvist, K., Mossberg, F., \& Lindgren, M. (2012). Eye movements and reading comprehension while listening to preferred and non-preferred study music. Psychology of Music, 40, 339-356. doi: 10.1177/0305735610387777

Juslin, P. N., \& Laukka, P. (2003). Communication of emotions in vocal expression and music performance: Different channels, same code? Psychological Bulletin, 129, 770-814. doi:10.1037/0033-2909.129.5.770

Juslin, P. N., \& Laukka, P. (2004). Expression, perception, and induction of musical emotions: A review and a questionnaire study of everyday listening. Journal of New Music Research, 33, 217-238. doi:10.1080/0929821042000317813

Juslin, P. N., \& Sloboda, J. A. (2001). Music and emotion. New York, NY: Oxford University Press. 
Kallio, S., Hyönä, J., Revonsuo, A., Sikka, P., \& Nummenmaa, L. (2011). The existence of a hypnotic state revealed by eye movements. PLoS ONE, 6: e26374. doi:10.1371/journal.pone.0026374

Kellaris, J. J., \& Mantel, S. P. (1996). Shaping time perceptions with background music: The effect of congruity and arousal on estimates of ad durations. Psychology \& Marketing, 13, 501-515.

Kreutz, G., Ott, U., Teichmann, D., Osawa, P., \& Vaitl, D. (2008). Using music to induce emotions: Influences of musical preference and absorption. Psychology of Music, $36,101-126$.

Lamont, A. (2011). University students' strong experiences of music: Pleasure, engagement, and meaning. Musicae Scientiae, 15, 229-249.

Lavine, R. A., Sibert, J. L., Gokturk, M., \& Dickens, B. (2002). Eye-tracking measures and human performance in a vigilance task. Aviation, Space, and Environmental Medicine, 73, 367-372.

Lopez, L., \& Malhotra, R. (1991). Estimation of time intervals with most preferred and least preferred music. Psychological Studies, 36, 203-209.

North, A. C., \& Hargreaves, D. J. (2008). The social and applied psychology of music. New York, NY: Oxford University Press.

Oh, J., Han, M., Peterson, B. S., \& Jeong, J. (2012). Spontaneous eyeblinks are correlated with responses during the Stroop task. PLoS ONE, 7, e34871. doi:10.1371/journal.pone.0034871

Posner, M. I., Snyder, C. R. R., \& Davidson, B. J. (1980). Attention and the detection of signals. Journal of Experimental Psychology: General, 109, 160-174.

Rayner, K. (1998). Eye movements in reading and information processing: 20 years of research. Psychological Bulletin, 124, 372-422. 
Rhodes, L. A., David, D. C., \& Combs, A. L. (1988). Absorption and enjoyment of music. Perceptual and Motor Skills, 66, 737-738.

Rouget, G. (1985). Music and trance. A theory of the relations between music and possession. Chicago, IL: The University of Chicago Press.

Schäfer, T., Fachner, J., \& Smukalla, M. (2013). Changes in the representation of space and time while listening to music. Frontiers in Psychology, 4, 1-15. doi:10.3389/fpsyg.2013.00508

Schäfer, T., \& Sedlmeier, P. (2011). Does the body move the soul? The impact of arousal on music preference. Music Perception: An Interdisciplinary Journal, 29, 37-50.

Schäfer, T., Sedlmeier, P., Städtler, C., \& Huron, D. (2013). The psychological functions of music listening. Frontiers in Psychology, 4, 1-33.

Schäfer, T., Smukalla, M., \& Oelker, S.-A. (2013). How music changes our lives. A qualitative study of the long-term effects of intense musical experiences. Psychology of Music. Advance online publication. doi:10.1177/0305735613482024

Schleicher, R., Galley, N., Briest, S., \& Galley, L. (2008). Blinks and saccades as indicators of fatigue in sleepiness warnings: Looking tired? Ergonomics, 51, 982-1010.

Smith, C. N., Hopkins, R. O., \& Squire, L. R. (2006). Experience-dependent eye movements, awareness, and hippocampus-dependent memory. Journal of Neuroscience, 26, 11304-11312.

Smith, D. T., Schenk, T., \& Rorden, C. (2012). Saccade preparation is required for exogenous attention but not endogenous attention or IOR. Journal of Experimental Psychology: Human Perception and Performance, 38, 1438-1447. doi:10.1037/a0027794 
Stern, J. A., Walrath, L. C. and Goldstein, R. (1984), The Endogenous Eyeblink. Psychophysiology, 21: 22-33. doi: 10.1111/j.1469-8986.1984.tb02312.x

Stuyven, E., Van der Goten, K., Vandierendonck, A., Claeys, K., \& Crevits, L. (2000). The effect of cognitive load on saccadic eye movements. Acta Psychologica, 104, 6985. doi:10.1016/S0001-6918(99)00054-2

Tart, C. (1971). On being stoned. A psychological study of marijuana intoxication. Oxford, England: Science \& Behaviour Books.

Tellegen, A., \& Atkinson, G. (1974). Openness to absorbing and self-altering experiences ("absorption"), a trait related to hypnotic susceptibility. Journal of Abnormal Psychology, 83, 268-277.

Vaitl, D., Birbaumer, N., Gruzelier, J., Jamieson, G. A., Kotchoubey, B., Kübler, A., ... Weiss, T. (2005). Psychobiology of altered states of consciousness. Psychological Bulletin, 131, 98-127. doi:10.1037/0033-2909.131.1.98

Zakay, D., \& Block, R. A. (1997). Temporal cognition. Current Directions in Psychological Science, 6, 12-16. doi:10.1111/1467-8721.ep11512604

Zatorre, R. J., \& Peretz, I. (2001). The biological foundations of music. New York, NY: New York Academy of Sciences.

Zingrone, N. L., Alvarado, C. S., \& Cardena, E. (2010). Out-of-body experiences and physical body activity and posture: Responses from a survey conducted in Scotland. Journal of Nervous and Mental Disease, 198, 163-165. doi:10.1097/NMD.0b013e3181cc0d6d

Zou, H., Müller, H. J., \& Shi, Z. (2012). Non-spatial sounds regulate eye movements and enhance visual search. Journal of Vision, 12, 1-18. 